\title{
The role of trust in information adoption in social commerce: A PLS approach
}

\author{
Tran Thi Thao Truc ${ }^{1 *}$, Nguyen Manh Tuan ${ }^{1}$ \\ ${ }^{1}$ Ho Chi Minh City University of Technology, Vietnam National University HCMC, Vietnam \\ *Corresponding author: truc.tran@mobifone.vn
}

\begin{tabular}{ll}
\hline \multicolumn{1}{c}{ ARTICLE INFO } & \multicolumn{1}{c}{ ABSTRACT } \\
\hline $\begin{array}{l}\text { DOI:10.46223/HCMCOUJS. } \\
\text { econ.en.8.2.163.2018 }\end{array}$ & $\begin{array}{l}\text { Social commerce (s-commerce or SC) is rapidly growing and } \\
\text { it is an increasingly favourite shopping way that customers adopt. } \\
\text { Based on the view of trust as a social reality and Petty and } \\
\text { Cacioppo's (1986) ELM theory, the paper proposes a theoretical }\end{array}$ \\
$\begin{array}{l}\text { Received: July 11 } \\
\text { Revised: July } 22^{\text {nd }}, 2018 \\
\text { Accepted: August } 16^{\text {th }}, 2018\end{array}$ & $\begin{array}{l}\text { model integrating information quality and social support to explain } \\
\text { information adoption through perceived consumer trust. A survey } \\
\text { with PLS-SEM analysis of 333 consumers shows that } 7 \text { out of } 11\end{array}$ \\
$\begin{array}{l}\text { Keywords: } \\
\text { information adoption, } \\
\text { information quality, social } \\
\text { commerce, social support, } \\
\text { trust }\end{array}$ & $\begin{array}{l}\text { 47.4\% of consumer information adoption. Moreover, as expected, } \\
\text { the information quality of s-commerce sites is always to be present } \\
\text { to build consumer trust in s-commerce sites and in members of s- } \\
\text { commerce sites. }\end{array}$
\end{tabular}

\section{Introduction}

The electronic commerce in general and social commerce (s-commerce or SC) in particular are characterized by the element of information (Pearlson, Saunders, \& Galletta, 2016). Accordingly, the information adoption of the transaction must be established so that users or customers can decide whether to participate or shop online and thus it is important both academically and practically (Erkan \& Evans, 2016). It should be noted that transactions in virtual communities have social identities and thus, hides the uncertainty and complexity of social interactions in general (Luhmann, 1979; Morvinski, Amir, \& Muller, 2017). To explore such social problems, trust was used as a central concept (Gefen, Karahanna, \& Straub, 2003; Lewis \& Weigert, 1985). According to Lewis and Weigert (1985), trust as a social reality of modern life is a property of the collective units (community), not of isolated individuals, and is therefore determined by social characteristics more than personality or even personal psychologic states. Functionally, trust is a strategic alternative or complementary possibly to rational prediction that is basically being applied to deal with the processes of social reality being more and more risky and rapidly changing (Lewis \& Weigert, 1985) such as e-commerce and s-commerce in recent years (Gefen et al., 2003; Morvinski et al., 2017). The paper proposes the use of trust instead of information usefulness as it is used in the majority of existing studies (e.g., Cheung, Lee, \& Rabjohn, 2008; Erkan \& Evans, 2016; Sussman \& Siegal, 2003) as a determinant to explain the information adoption of the customer in s-commerce. Another 
notable feature of the information in s-commerce is the increasingly important role of e-WOM of the community of respective websites, including buyers, potential customers, service \& product experts and other stakeholders (Hussain et al., 2018; Kim \& Park, 2013). These types of information, along with official information from the social networking site's owner, form two kinds of information that must be considered when researching information adoption of social network users in general (Morvinski et al., 2017).

After all, social support, an essential element of social interactions in s-commerce, can actively support the understanding and evaluation of the transactions of potential buyers (Liang, Ho, Li, \& Turban, 2011). Thus, the feelings of social support of the customer will also be integrated into the research model of this paper - accordingly, the information quality and social support will shape the trust and hence leading to the information adoption of the customer in s-commerce.

The research settings chosen are the online transactions on the s-commerce sites in Vietnam of individuals mainly in Ho Chi Minh City and Hanoi - the two largest trade centers in Vietnam.

The structure of the paper is as follows. The next part is the theoretical basis to form a research model in which basic concepts such as information quality, social support, trust and information adoption are presented. The next part is the research methodology and then the research results are presented. Finally, theoretical contributions, managerial implications, as well as constraints and further research directions, are discussed.

\section{Literature review}

\section{Social commerce}

Social commerce (s-commerce) is often understood as a form of commerce in a social media context, and, thus, is converging both online and offline environment (C. Wang \& Zhang, 2012).

In a typical way, s-commerce shows itself as a kind of Internet-based commercial applications, using social media and Web 2.0 technologies which support social interactions and user-generated contents in order to assist consumers in their decision making and buying and selling of products and services within online and even traditionally marketplaces (Huang \& Benyoucef, 2013). Such environments or marketplaces would be helpful to identify two kinds of social commerce: online and offline (Zhong, 2012), or alternatively, onsite and offsite (Stulec, Petljak, \& Naletina, 2018). While the former refers to the traditional e-commerce platform that the incorporate social sharing features and functionality on the seller's or provider's website, the latter indicates the commerce forms that are on social platform such as Facebook, Twitter, Instagram, etc. rather than on the seller's or provider's website (Stulec et al., 2018; Zhong, 2012). However, from a practitioner's perspective, it is commonly agreed that both kinds of social commerce would accommodate six Cs of social technologies, which are Content, Community, Commerce, Context, Connection, Conversation (Bankinter, 2012). It should be noted that, while the former three ' $C$ ' refers to the original 3 ' $C$ ' of e-commerce, the latter three ' $\mathrm{C}$ ' mention the updates for an era of social sharing and support. Thus, to truly reflect 
such updates, this study takes the social perspective for viewing trust as a social reality rather than a traditionally psychological expression and for adopting social support including informational support and emotional support as main antecedents for social trust.

\section{Theory of ELM (Elaboration Likelihood Model)}

The persuasive process in shaping human perceptions and behavior is often considered in the dual-process theory of social psychology (Bhattacherjee \& Sanford, 2006). Accordingly, the formation of individual attitudes in addition to being influenced largely by the process of scrutinizing the judgment-relevant information externally is influenced by heuristic cues, with less effortful processing.

The theory of ELM (Petty \& Cacioppo, 1986), also a dual-process, is a general theory of attitude change and suggests that the process of changing individual attitudes toward an issue through two routes: the central route is presented by the information quality related to the issue and carefully considered by the individual and peripheral route is presented by other relevant cues such as emotion, attractiveness or persuasiveness of the source.

In essence, the central route refers to the process of scrutinizing the information of the individual in a relatively objective manner, i.e., thoughtful consideration of the information is the decision to persuade the individual. In contrast, the peripheral route refers to the change of attitude in a relatively biased manner, i.e., initial evaluations or prejudices play an important role in persuading individuals.

Petty and Cacioppo (1986) introduces the concept of likelihood of elaboration to reflect individual attention when considering arguments related to the issue under consideration, and this depends on the condition of information processing. The likelihood of elaboration will be high when the communication environment supports the individual for the allocation of considerable cognitive resources to all relevant aspects of the issue, thereby forming a corresponding attitude on the issue under consideration. Objective processing helps to discover the true value of information and thus the stronger the argument is, the more convincing it is and vice versa, bias processing usually produces the type of prejudiced thought or emotion or initial attitudes of the individual (Petty \& Cacioppo, 1986)

Then, attitudes, understood as the individual's response to the stimulus, are presented both emotionally (e.g., emotional reactions, instantaneous feelings) and cognitively (e.g., perceptual responses, knowledge) (Breckler, 1984). Two emotional and cognitive components of attitudes can be applied to individual persuasion studies, and the integration of these two components creates a stable or equilibrium state or not? In the ELM theory, Petty and Cacioppo (1986) defines attitudes as general perceptions of the individual based on the emotional, cognitive experiences and be able to affect or direct cognitive and emotional processes of the individual. Changing attitudes generated from issue relevant arguments will last longer and predict behavior better than attitude changes generated from peripheral cues (Petty \& Cacioppo, 1986). Finally, the ELM theory shows that object adoption can be achieved after attitudes toward that object are shaped through both the central route and peripheral route. 


\section{Information adoption}

Adoption theory describes the process an individual must undergo when deciding to perform an action for the first time (as distinguished from repetitive behavior) (Sussman \& Siegal, 2003) based on information, ideas or the technology they receive (Rabjohn, Cheung, \& Lee, 2008). It is possible to view the process of information adoption as the internal phase of knowledge transfer, in which explicit information is transferred to tacit information or internalized knowledge (Nonaka, 1994).

This paper follows Sussman and Siegal (2003) in defining information adoption as a form of technology acceptance that is proposed in the well-known technology acceptance model (TAM) (see Davis, 1989). Whereby, information adoption is understood as the use of information for subsequent decision making, similar to the intention to use technology that results in the behavior using the technology in the stated TAM model (Sussman \& Siegal, 2003).

In online commerce, Rabjohn et al. (2008) argue that information adoption is an acknowledgment of this information in a consciously or subconsciously manner and using this information in subsequent purchase decisions. In addition, information adoption is also understood as the use of targeted information and, moreover, is one of the most important activities when individuals actively participate in the virtual community (Cheung et al., 2008). For example, individuals seeking feedback and comments posted by others in the community before they make a purchase decision or posting questions or concerns through the virtual community for the advices (Sussman \& Siegal, 2003).

\section{Trust and information adoption}

From the point of view of sociologists, trust is a social reality and is a multidimensional concept, typically cognitive and emotional trust (Lewis \& Weigert, 1985). First, the cognitive trust will discriminate among individuals or organizations that are trustworthy, distrusted and unknown (Lewis \& Weigert, 1985) and Luhmann (1979 as cited in Lewis \& Weigert, 1985) describes the cognitive process as "overdrawing" on the informational bases. Emotional trust is the emotional bond between individuals and emotional base that is complementary to its cognitive base (Lewis \& Weigert, 1985).

Lewicki and Bunker (1996) defined trust as the positive expectation of the individual about the actions of others toward him in potentially risky situations. By reducing the complexity of social relationships, trust is the basis for social exchanges, enabling social interactions to occur in a more reliable and simplified way (Simmel, 2004). For online shopping, customers must rely on electronic information and often have limited information resources, so they may be compromised by incomplete or distorted information from the seller and the third component (Lee, 1998, as cited in Pavlou, 2003). To reduce the uncertainty and complexity of virtual transactions, they often rely on the trust of their suppliers (Fang, Chiu, \& Wang, 2011), which is still considered essential to understand the behavior of exchange between seller and buyer (Pavlou, 2003). In addition, in s-commerce, buyers also rely on the trust of virtual community members to gain advice as well as other information related to the transaction experience (Chen \& Shen, 2015). Accordingly, this paper looks at two types of trust 
- the trust in SC site that is understood as the belief of the buyer that they can receive reliable information as expected from this s-commerce site (Pavlou \& Gefen, 2004); the trust in members of SC site that is understood as an individual's belief that other members of the scommerce community will exchange and deal with them in a kind and decent way (Chen \& Shen, 2015). In comparison with Simmel's (2004) dimensions of trust, it can be seen that while trust in SC site is cognitive trust (Lewis \& Weigert, 1985), which is inherent in the consideration and evaluation through the interaction between the individual and the person they trust (Gefen, 2000), trust in members of SC site is emotional trust (Lewis \& Weigert, 1985), there is derived from mere personal, spontaneous beliefs about the kindness that other people will treat them (Möllering, 2001). Moreover, in view of the multi-dimensional attitude of Breckler (1984), trust in SC site is the cognitive attitude and trust in the members of SC site is the emotional attitude.

Recall that ELM theory has shown that the formation of attitudes toward an object facilitates the corresponding behavior on that object. From here, with the notion of trust in SC site and trust in members of SC site revolve around transaction information from s-commerce site and from members of s-commerce site correspondingly, the following hypotheses are proposed:

Hla: Trust in SC site has a positive impact on the information adoption of customers

H1b: Trust in members of SC site has a positive impact on the information adoption of customers

In addition, Luhman, based on Lewis and Weigert (1985), asserts that system trust ultimately depends on personal trust. In more detail, Stewart (2003) believes that trust can be transferred between objects: starting with trusting an entity (as a member of the s-commerce community), one will come to trust other relevant entities (such as the s-commerce sites). Empirically, the relationship between member trust and community trust is also confirmed in Chen, Zhang, and Xu (2009), Chen and Shen (2015), or Pavlou and Gefen (2004). So the following hypothesis is suggested:

H1c: Trust in members of SC site has a positive impact on the trust in SC site

\section{Information quality of social commerce site}

Information quality is understood as the customer's perceptions of the characteristics and presentation of information and it deals with attributes such as relevance, understandability, accuracy, completeness and timeliness in relation to their purchase decision (Fang et al., 2011).

In the s-commerce, information quality becomes more specific as information about products and services is offered on both sides - from direct suppliers and from the broad range of customers who have already shopped, potential customers and other partners (Kim \& Park, 2013). This paper examines two information quality that corresponds to the two sources of information: the information quality of SC site (provided by the business) and the $e-W O M$ quality (widely disseminated comments and opinions of customers in the form of electronic word of mouth on s-commerce sites). While the first type of information relates to the characteristics and specifications of the product or service, price, supplier, warranty, after-sales 
and billing, the second type of information is more about evaluating, ranking and discussing shopping and consuming experiences of members on the s-commerce website (Cheung et al., 2008). It is important to note that both sources of information are necessary for potential buyers of the s-commerce sites to consult and evaluate before they make a purchase decision (Hussain et al., 2018).

Next, in e-commerce transactions, a principle-agency perspective can be used to explain objective inconsistencies in the employer-employee relationship, which induce uncertainty (Pavlou, Liang, \& Xue, 2007). The principle-agency view based on agency theory that explains the relationship between employer and employee, used by information economists for imperfect information markets (Akerlof, 1970, as cited in Pavlou et al., 2007) and specifically for virtual transactions in socio-economic systems that exist asymmetric information, fears of opportunism and bounded rationality (Milgrom \& Roberts, 1992, as cited in Pavlou et al., 2007). Principle agency views can be applied in the relationship between the seller and the buyer (the buyer is the principle, the seller is the agency) where the buyer authorizes the seller who has more information about the product \& service than the buyer and the buyer cannot fully monitor the behavior of the seller, resulting in two issues of information: adverse selection (hidden information) or moral hazard (hidden action) (Pavlou et al., 2007). From the point of view of information system operators, the uncertainty in the principle-agency relationship is due to the information problem, which can be minimized if the information system is properly used (Pavlou et al., 2007). In the context of social commerce, in addition to the products $\&$ services information provided by the sales company on the s-commerce website, the social network is a means by which the buyer community can exchange e-WOM about products \& services as well as e-WOM related to the behavior of the seller in the online purchase transaction. Consequently, e-WOM can help minimize hidden information and hidden actions that increase the reliability of online transactions.

The consideration of these bases, according to the ELM theory, is carried out according to the central route: the process of scrutinizing issue-relevant arguments in a relatively objective manner aimed at convincing individuals about the authenticity of the issue. In other words, the information quality is gathered around the issue in order to shape positive (or negative) attitudes about the issue in question. For example, the trust in members of SC sites can be established when the content of the relevant s-commerce sites is transparent, rich or the s-commerce community's comments are multi-dimensional positively.

Empirically, the clarity and completeness of the information content of the s-commerce site has been affirmed as the main reason for the customer's trust in this s-commerce site (Liao, Palvia, \& Lin, 2006), or the information quality of SC sites, along with some other characteristics of s-commerce sites, is a factor that strongly influences the customers' trust (Kim \& Park, 2013).

From here, the following hypotheses are proposed:

H2: Information quality of SC site has a positive impact on (a) the trust in SC site, (b) the trust in member of SC site 
H3: e-WOM quality has a positive impact on (a) the trust in SC site, (b) the trust in member of SC site

\section{Social support in the online community}

Social support is the basic concept of social support theory that is suggested to explain the social relationships that affect the activity of the individual concerned (Y. Wang \& Hajli, 2014). Social support is information that makes people believe that they are interested, loved, valued, and they are members of a network of mutual support and social support facilitates the individual when confronted with crisis and adapted to change (Cobb, 1976). In more detail, Mattson and Hall (2011) proposed social support as a process of social interaction through psychological or physical exchanges to improve individual problem-solving capacities.

Schaefer et al. (1981, as cited in Mattson \& Hall, 2011) describe five types of social support including informational support, emotional support, tangible support, network support and esteem support. Since interaction on the Internet is essentially virtual, online social support is intrinsically invisible (Liang et al., 2011) and individuals are also intangible, so online social support is considered non- verbal and non-verbal communication to convey emotional and informational messages that reduce mental stress for the recipient (Pleif \& Zaphiris, 2009, as cited in Chen \& Shen, 2015). Mattson and Hall (2011) argue that individuals are more likely to receive supportive communication from social networks and individuals with more social connections are more likely to engage with social networks. Thus, the online community can bring social value to users and social support is an important social value that Internet users acquire (Liang et al., 2011). However, members of the online community usually only give and receive informational and emotional support (Mattson \& Hall, 2011) so in the context of scommerce, the social support is mainly informational support and emotional support (Chen \& Shen, 2015; Liang et al., 2011; Y. Wang \& Hajli, 2014).

Informational support is a type of support where individuals receive useful advice or guidance that can help them solve problems, generate new ideas, or help them make better decisions (Liang et al., 2011). It should be noted that, while the informational quality refers to perceptions through the assessment of the usefulness of the information content itself that they receive (such as the level of comprehension of a buying advice), then informational support is an assessment of how often or frequently people are being helped or provided with content or ideas from virtual community members (such as how often they get advice when buying a product).

Emotional support is the type of support through which individuals receive attention or understanding in order to motivate them to make the effort to solve the problem. As well as informational support, emotional support expresses a heavy consideration of the customer's feelings when communicating and interacting on s-commerce sites. Thus, these emotional considerations may have a bias in personal persuasion as the ELM theory has identified, and therefore, both forms of informational support and emotional support do the role of the peripheral route in shaping attitudes towards problem-solving. More specifically, this biased influence process occurs when customer's trust primarily comes from the feeling of being 
motivated and interested when they participate in s-commerce sites rather than from the process of assessment and analysis of the relevant information quality. Although there is no argument, social support will provide an emotional support environment that will convince and direct customers to form positive attitudes toward the s-commerce site, in this case, is their trust.

According to Weber, Johnson, and Corrigan (2004), strong forms of social support make individuals feel coherent and thereby shape their trust with members of the virtual community. In addition, social support forms provide psychological benefits to online consumers and build a positive attitude between them and the s-commerce site such as trust and commitment to the s-commerce site (Liang et al., 2011). From here, the following research hypotheses are formed:

H4: Informational support has a positive impact on (a) the trust in SC site, (b) the trust in member of SC site

H5: Emotional support has a positive impact on (a) the trust in SC site, (b) the trust in member of SC site

\section{Research methodology}

\section{Data collection}

The data is collected by convenient sampling via questionnaires distributed in two forms - the Google Form on Facebook and the hardcopy questionnaire to individuals who participated in s-commerce sites mainly in Ho Chi Minh City and Hanoi. With a total of more than 350 receipts after more than two months of surveying, after cleaning up, eliminating invalid questionnaires (the questionnaires lacked information or were matched for all questions), the author remains 333 questionnaires eligible for further analysis.

Demographic statistics show that the proportion of male respondents was $61 \%$, female $39 \%$; age group, age under 25 years old accounted for 29\%, age 25 to 35 accounted for $44 \%$, age 36 to 50 accounted for $23 \%$, age over 50 accounted for $3 \%$; income of under 5 million $\mathrm{VND} /$ month accounted for $20 \%$, income 5 to 10 million VND accounted for 26\%, income 10 to 15 million VND accounted for $24 \%$, income 15 to 20 million VND accounted for $14 \%$, income over 20 million VND/month accounted for $16 \%$.

\section{Measures}

All the measures in this study have been used and validated in prior studies with some preliminary qualitative adjustments and minor changes in the wordings that were made so as to fit the current research context. Specifically, "Information Quality" is measured with items adapted from Fang et al. (2011), "Informational Support" and "Emotional Support" are measured with items adapted from Liang et al. (2011), "Trust in member of SC site" and "Trust in SC site" are measured with items adapted from Chen and Shen (2015), and Fang et al. (2011), "Information Adoption" is measured with items adapted from Cheung et al. (2008), and Lal (2017). Instruments for all the constructs were phrased on a five-point Likert scales, anchored from " $1=$ strongly disagree" and "5=strongly agree". 


\section{Data analysis}

The paper uses quantitative methods and Structural Equation Model (SEM) with the popular Partial Least Squared (PLS) technique. The measurement model (inner) and the structural model (outer) will be assessed simultaneously (Hair, Hult, Ringle, \& Sarstedt, 2014). The software used is smartPLS 3.0.

\section{Research findings}

\section{Measurement model}

The measurement model was examined in terms of convergent validity and discriminant validity. Convergent validity of all constructs can be assessed by examining the composite reliability (CR), factor loadings and the average variance extracted (AVE) (Hair et al., 2014). Factor loading of 0.65 or above (Table 1), CR of 0.7 or above and AVE of more than 0.5 (Table 2) indicate clearly that convergent validity is acceptable. Discriminant validity was assessed by checking if the square root of the average variance extracted for each construct is greater than the correlations between that construct and all other constructs (Hair et al., 2014). Table 2 presents the correlation matrix of the constructs and the square root of the AVE for each construct. The results demonstrate satisfactory discriminant validity of the measurements.

\section{Table 1}

Factor loadings of measures

\begin{tabular}{|l|l|c|}
\hline & \multicolumn{1}{|c|}{ Measure } & $\begin{array}{c}\text { Factor } \\
\text { Loading }\end{array}$ \\
\hline Construct & Information Quality of SC site & $\mathbf{0 . 6 9 6}$ \\
\hline InfoQual1 & $\begin{array}{l}\text { Information provided by the social commerce site is } \\
\text { relevant to my purchase decisions. }\end{array}$ & 0.721 \\
\hline InfoQual2 & $\begin{array}{l}\text { Information provided by the social commerce site is easy to } \\
\text { comprehend. }\end{array}$ & 0.787 \\
\hline InfoQual3 & Information provided by the social commerce site is accurate. & 0.798 \\
\hline InfoQual4 & Information provided by the social commerce site is complete. & $\mathbf{0 . 6 5 1}$ \\
\hline InfoQual5 & Information provided by the social commerce site is timely. & 0.705 \\
\hline Construct & e-WOM Quality & Dropped \\
\hline eWOMQual1 & e-WOM is relevant to my purchase decisions. & 0.791 \\
\hline eWOMQual2 & e-WOM is easy to comprehend. & 0.702 \\
\hline eWOMQual3 & e-WOM is accurate. & 0.756 \\
\hline eWOMQual4 & e-WOM is complete. & \\
\hline eWOMQual5 & e-WOM is timely. & \\
\hline
\end{tabular}




\begin{tabular}{|c|c|c|}
\hline & Measure & $\begin{array}{r}\text { Factor } \\
\text { Loading }\end{array}$ \\
\hline Construct & Informational Support & \\
\hline InfoSupp1 & $\begin{array}{l}\text { On the social commerce site, some people would offer } \\
\text { suggestions when I needed help. }\end{array}$ & 0.761 \\
\hline InfoSupp2 & $\begin{array}{l}\text { When I encountered a problem, some people on the social } \\
\text { commerce site would give me information to help me } \\
\text { overcome the problem. }\end{array}$ & 0.895 \\
\hline InfoSupp3 & $\begin{array}{l}\text { When faced with difficulties, some people on the social } \\
\text { commerce site would help me discover the cause and } \\
\text { provide me with suggestions. }\end{array}$ & 0.869 \\
\hline Construct & Emotional Support & \\
\hline EmotSupp1 & $\begin{array}{l}\text { When faced with difficulties, some people on the social } \\
\text { commerce site are on my side with me. }\end{array}$ & 0.823 \\
\hline EmotSupp2 & $\begin{array}{l}\text { When faced with difficulties, some people on the social } \\
\text { commerce site listened to me talk about my private } \\
\text { feelings. }\end{array}$ & 0.862 \\
\hline EmotSupp3 & $\begin{array}{l}\text { When faced with difficulties, some people on the social } \\
\text { commerce site comforted and encouraged me }\end{array}$ & 0.876 \\
\hline EmotSupp4 & $\begin{array}{l}\text { When faced with difficulties, some people on the social } \\
\text { commerce site expressed interest and concern in my well- } \\
\text { being. }\end{array}$ & 0.811 \\
\hline Construct & Trust in member of SC site & \\
\hline MembTrus1 & $\begin{array}{l}\text { I trust the information provided by member of social } \\
\text { commerce site }\end{array}$ & 0.846 \\
\hline MembTrus2 & $\begin{array}{l}\text { Members in social commerce site are truthful in dealing } \\
\text { with one another. }\end{array}$ & 0.860 \\
\hline MembTrus3 & $\begin{array}{l}\text { Members in social commerce site will always keep the } \\
\text { promises they make to one another. }\end{array}$ & 0.730 \\
\hline Construct & Trust in SC site & \\
\hline CommTrus1 & $\begin{array}{l}\text { Based on my experience with social commerce site in the past, } \\
\text { I know it is trustworthy. }\end{array}$ & 0.806 \\
\hline CommTrus2 & I trust the information provided by social commerce site & 0.808 \\
\hline CommTrus3 & $\begin{array}{l}\text { Based on my experience with social commerce site in the past, } \\
\text { I know it is not opportunistic. }\end{array}$ & 0.788 \\
\hline
\end{tabular}




\begin{tabular}{|l|l|c|}
\hline & \multicolumn{1}{|c|}{ Measure } & $\begin{array}{c}\text { Factor } \\
\text { Loading }\end{array}$ \\
\hline CommTrus4 & $\begin{array}{l}\text { Based on my experience with social commerce site in the past, } \\
\text { I know it keeps its promises to customers. }\end{array}$ & 0.742 \\
\hline Construct & Information Adoption & 0.780 \\
\hline InfoAdop1 & $\begin{array}{l}\text { I will closely follow information of social commerce site when } \\
\text { I want to buy product. }\end{array}$ & 0.829 \\
\hline InfoAdop2 & $\begin{array}{l}\text { I will consider the shopping experiences of my friends } \\
\text { in social commerce site when I want to shop }\end{array}$ & 0.735 \\
\hline InfoAdop3 & $\begin{array}{l}\text { I will ask my friends in social commerce site to provide me } \\
\text { with their suggestions before I go for shopping }\end{array}$ & $\mathbf{0 . 6 8 1}$ \\
\hline InfoAdop4 & $\begin{array}{l}\text { I am willing to buy the products recommended by my } \\
\text { friends in social commerce site. }\end{array}$ & \\
\hline
\end{tabular}

Source: The researcher's data analysis

\section{Table 2}

Convergent validity and discriminant validity

\begin{tabular}{|l|c|l|c|c|c|c|c|c|c|}
\hline CR & AVE & Construct & InfoQual & eWOMQual & InfoSupp & EmotSupp & CommTrus & MembTrus & InfoAdop \\
\hline 0.852 & 0.537 & InfoQual & $\mathbf{0 . 7 3 3}$ & & & & & & \\
\hline 0.828 & 0.546 & eWOMQual & 0.579 & $\mathbf{0 . 7 3 9}$ & & & & & \\
\hline 0.880 & 0.712 & InfoSupp & 0.356 & 0.455 & $\mathbf{0 . 8 4 4}$ & & & & \\
\hline 0.908 & 0.711 & EmotSupp & 0.334 & 0.427 & 0.703 & $\mathbf{0 . 8 4 3}$ & & & \\
\hline 0.866 & 0.618 & CommTrus & 0.574 & 0.404 & 0.342 & 0.364 & $\mathbf{0 . 7 8 6}$ & & \\
\hline 0.855 & 0.663 & MembTrus & 0.428 & 0.456 & 0.463 & 0.581 & 0.605 & $\mathbf{0 . 8 1 4}$ & \\
\hline 0.843 & 0.575 & InfoAdop & 0.487 & 0.428 & 0.335 & 0.347 & 0.683 & 0.498 & $\mathbf{0 . 7 5 8}$ \\
\hline
\end{tabular}

Source: The researcher's data analysis

\section{Structural model}

The bootstrap technique $(\mathrm{n}=4999)$ was used to evaluate the hypotheses and the results showed that 7 out of 11 hypotheses were supported (Figure 1). In general, information adoption is much more influenced by trust in SC site $(\beta=0.601)$ than trust in member of SC site $(\beta=$ $0.135)$. In addition, these two aspects of trust explain well information adoption of the customer $(\mathrm{R} 2=47.4 \%)$. 


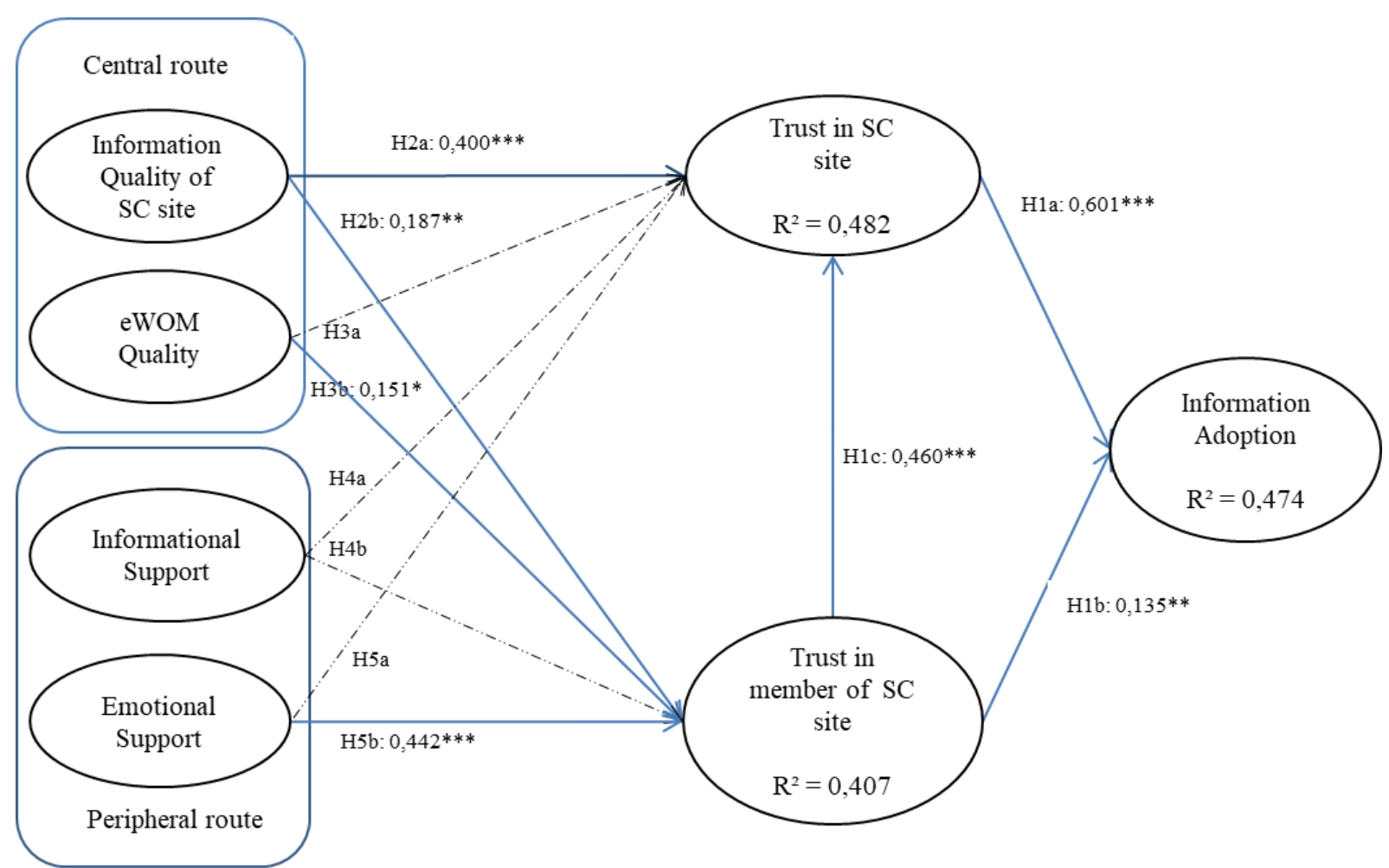

Notes: $\quad(1) * \mathrm{p}<0,05 ; * * \mathrm{p}<0,01 ; * * * \mathrm{p}<0,001$

(2) dotted: hypothesis is not supported

Figure 1. Results of the PLS analysis

\section{Discussion}

The paper based on ELM theory tests two routes affecting the trust of customers, in which the central route includes the information quality of SC site and e-WOM quality, the peripheral route consists of Informational Support and Emotional Support. For the central route, three out of four hypotheses are supported, compared to only one of four hypotheses supported by the peripheral route.

Firstly, the research results confirm the role of trust for customer's information adoption, accordingly that trust in SC site has a significantly higher impact (0.601) than trust in member of SC site (0.135). This reveals that the basic requirement for customer's information adoption is that they can trust the information provided by the supplier's official s-commerce site, followed by information from members of s-commerce site.

Furthermore, this finding is consistent with many previous papers on information adoption in which the most popularantecedent is information usefulness: trust in this study may explain more than $47 \%$ of customer's information adoption comparing to information usefulness that explained around $22 \%$ by Sussman and Siegal's (2003) and $88 \%$ by Erkan and Evan's (2016). 
In addition, the paper also found that, for different objects of trust, the effect of each route of ELM theory is different. In particular, trust in member of SC site has been impacted significantly higher by an element of peripheral route, namely, emotional support $(\beta=0.442)$ than two elements of the central route, namely, information quality of SC site and eWOM quality $(\beta=0.151)$. Meanwhile, trust in SC site is affected only by the central route, namely, information quality of SC site $(\beta=0.400)$. Thus, it can be concluded that trust in members of $S C$ site is based on a more emotional biased thinking, while trust in SC site is dominated by rational thinking.

Next, the role of informational support has not been confirmed (hypotheses H4a \& H4b are rejected), it means that in s-commerce, emotional support is the primary ingredient for social support in shaping customer's trust in members of SC site. This result may be a significantly initial finding to (i) work of Chen and Shen (2015) that informational support influences customer trust in general and emotional support affects to trust in member and (ii) work of Kim and Park's (2013) that two elements of information quality help building trust in the buyer. This can be explained as follows - in Chen and Shen's (2015) study, when there are no elements of information quality belonging to central route, two components of social support exhibit its full role and in Kim and Park's (2013) study, when there are no factors of social support, information quality influences positively customer trust. However, in the presence of information quality to build trust as in this study, information quality that the user absorbs has a dominant role compared to the form or volume of information they receive.

Finally, trust in members has a great impact on trust in SC site $(\beta=0.46)$ reaffirmed the work of Chen and Shen (2015), Chen et al. (2009) and reinforced the view of Luman that the system trust ultimately depends on personal trust (Lewis \& Weigert, 1985). From this, it can be concluded that trust in members of SC site is one of the important ingredients for forming trust in SC site of customers.

\section{Conclusion}

\section{Theoretical contributions}

The paper has the following two theoretical contributions. First, traditional information adoption is most often explained by the rational prediction that is the basis of the TAM model (Gefen et al., 2003); accordingly, information usefulness is considered to be the core explanation for user acceptance (Erkan \& Evans, 2016; Sussman \& Siegal, 2003). Meanwhile, this study, based on the viewpoint of trust as a social reality (Lewis \& Weigert, 1985), especially in the modern context focusing on broader social connectivity (Hsu, Chang, \& Yen, 2011; Sohn, 2014), has successfully proposed the use of trust comprising two components trust in SC site (cognitive) and trust in member of SC site (emotional) - as the primary driver for the information adoption.

Second, the ELM theory-based paper proposed two routes to explain the formation of trust through cognition (information quality) and emotion (social support). This may be considered as a significant complement to most previous studies where predictors, although of diverse origins (such as knowledge-based trust, institution-based trust or calculative based trust) 
(see Gefen et al., 2003), emotional backgrounds for the formation of trust are lacking. So here one can say that the paper is one of the first empirical studies taking the view of trust as the social reality in which trust in real life is a mixture of rational and emotional attitudes (see Lewis \& Weigert, 1985).

\section{Managerial implications}

This study may suggest several managerial applications. Firstly, for information adoption, by trust in SC site has a remarkable effect, the administrators of s-commerce sites should focus on building user trust on the site itself. This, in turn, requires businesses to invest in information quality of SC site (H2a hypothesis) (such as continuous information updating, enriching the content such as comparison of products' information between suppliers ...).

Secondly, businesses need to take care of their fanpage community in order to promote the emotional support from the community for each consumer (H5b hypothesis) to build mutual trust in the community through which it builds trust in the relevant s-commerce site (such as providing a lot of interesting interactive tools, reinforcing forums on the site, helping the community to interact and exchange information, easily share feelings with each other, etc.).

Thirdly, s-commerce site managers also need to increase the promotion of products and services and/or link between media channels and s-commerce sites to ensure $e$-WOM quality in the consumer community in order to reinforce trust in members of SC site (H3b hypothesis).

Finally, with the fact that both trust in SC site and trust in member of SC site play an important role for information adoption, given that both e-commerce web users and Facebook (f-commcerce), or Twitter (t-commerce) users are in a great way increasing (Bankinter, 2012; Stulec et al., 2018), it should be better for businesses to combine their onsite with their offsite activities to attract more and more established users and potential customers into their social commerce endeavor.

\section{Limitations and future research directions}

The paper currently only recommends customers' trust as the only determinant for their information adoption in s-commerce, as opposed to many previous works where only information usefulness is used as antecedent. At this point, further studies might have some opportunities to combine trust and information usefulness to predict information adoption of customers. This combination is acceptable because both contain the cognitive aspects of individual users (Gefen et al., 2003).

In addition, trust in this study is approached from a social point of view and bypass the tendency of trust originating in more psychological approaches (Gefen et al., 2003). Accordingly, another possible avenue for further studies is to examine the dispositional trust of the customer to explain their information adoption (Hsu et al., 2011). 


\section{References}

Bankinter. (2012). Social technologies - The power of conversations on the Net. Retrieved January 15, 2018, from Bankinter Foundation of Innovation, Spain website: https://www.fundacionbankinter.org/documents/20183/42758/Social+Technologies/374 39e75-7b0a-486d-a3f5-83bfa78605d1

Bhattacherjee, A., \& Sanford, C. (2006). Influence processes for information technology acceptance: An elaboration likelihood model. MIS Quarterly, 30(4), 805-825. doi: $10.2307 / 25148755$

Breckler, S. J. (1984). Empirical validation of affect, behavior, and cognition as distinct components of attitude. Journal of Personality and Social Psychology, 47(6), 1191-1205. doi:10.1037//0022-3514.47.6.1191

Chen, J., \& Shen, X.-L. (2015). Consumers' decisions in social commerce context: An empirical investigation. Decision Support Systems, 79, 55-64. doi:10.1016/j.dss.2015.07.012

Chen, J., Zhang, C., \& Xu, Y. (2009). The role of mutual trust in building members' loyalty to a C2C platform provider. International Journal of Electronic Commerce, 14(1), 147-171. doi:10.2753/JEC1086-4415140105

Cheung, C. M., Lee, M. K., \& Rabjohn, N. (2008). The impact of electronic word-of-mouth: The adoption of online opinions in online customer communities. Internet Research, 18(3), 229-247. doi:10.1108/10662240810883290

Cobb, S. (1976). Social support as a moderator of life stress. Psychosomatic Medicine, 38(5), 300-314.

Davis, F. D. (1989). Perceived usefulness, perceived ease of use, and user acceptance of information technology. MIS Quarterly, 13(3), 319-340.

Erkan, I., \& Evans, C. (2016). The influence of e-WOM in social media on consumers' purchase intentions: An extended approach to information adoption. Computers in Human Behavior, 61, 47-55. doi:10.1016/j.chb.2016.03.003

Fang, Y. H., Chiu, C. M., \& Wang, E. T. (2011). Understanding customers' satisfaction and repurchase intentions: An integration of IS success model, trust, and justice. Internet Research, 21(4), 479-503. doi:10.1108/10662241111158335

Gefen, D. (2000). E-commerce: The role of familiarity and trust. Omega, 28(6), 725-737. doi:10.1016/S0305-0483(00)00021-9

Gefen, D., Karahanna, E., \& Straub, D. W. (2003). Trust and TAM in online shopping: An integrated model. MIS Quarterly, 27(1), 51-90. doi:10.2307/30036519

Hair, J. F., Jr., Hult, G. T. M., Ringle, C., \& Sarstedt, M. (2014). A primer on partial least squares structural equation modeling (PLS-SEM). California, US: Sage Publications. 
Hsu, M. H., Chang, C. M., \& Yen, C. H. (2011). Exploring the antecedents of trust in virtual communities. Behaviour \& Information Technology, 30(5), 587-601. doi:10.1080/0144929X.2010.549513

Huang, Z., \& Benyoucef, M. (2013). From e-commerce to social commerce: A close look at design features. Electronic Commerce Research and Applications, 12(4), 246-259. doi:10.1016/j.elerap.2012.12.003

Hussain, S., Guangju, W., Jafar, R. M. S., Ilyas, Z., Mustafa, G., \& Jianzhou, Y. (2018). Consumers' online information adoption behavior: Motives and antecedents of electronic word of mouth communications. Computers in Human Behavior, 80, 22-32.

Kim, S., \& Park, H. (2013). Effects of various characteristics of social commerce (s-commerce) on consumers' trust and trust performance. International Journal of Information Management, 33(2), 318-332. doi:10.1016/j.ijinfomgt.2012.11.006

Lal, P. (2017). Analyzing determinants influencing an individual's intention to use social commerce website. Future Business Journal, 3(1), 70-85. doi:10.1016/j.fbj.2017.02.001

Lewicki, R. J., \& Bunker, B. B. (1996). Developing and maintaining trust in work relationships. In R. M. Kramer, \& T. R. Tyler (Eds.), Trust in organizations: Frontiers in theory and research (pp. 114-139). California, US: Sage Publications.

Lewis, J. D., \& Weigert, A. (1985). Trust as a social reality. Social Forces, 63(4), 967-985. doi:10.2307/2578601

Liang, T. P., Ho, Y. T., Li, Y. W., \& Turban, E. (2011). What drives social commerce: The role of social support and relationship quality. International Journal of Electronic Commerce, 16(2), 69-90. doi:10.2753/JEC1086-4415160204

Liao, C., Palvia, P., \& Lin, H. N. (2006). The roles of habit and web site quality in e-commerce. International Journal of Information Management, 26(6), 469-483. doi:10.1016/j.ijinfomgt.2006.09.001

Luhmann, N. (1979). Trust and power. Toronto, Canada: Wiley.

Mattson, M., \& Hall, J. G. (2011). Linking Health Communication with social support. In M. Mattson, \& J. G. Hall (Eds.), Health as communication nexus: A service-learning approach (pp. 181-218). Dubuque, IA: Kendall Hunt Publishing Company.

Möllering, G. (2001). The nature of trust: From Georg Simmel to a theory of expectation, $\begin{array}{llll}\text { interpretation and } \quad \text { Suspension. } & \text { Sociology, }\end{array}$ doi:10.1177/S0038038501000190

Morvinski, C., Amir, O., \& Muller, E. (2017). "Ten million readers can't be wrong!," or can they? On the role of information about adoption stock in new product trial. Marketing Science, 36(2), 290-300. doi:10.1287/mksc.2016.1011

Nonaka, I. (1994). A dynamic theory of organizational knowledge creation. Organization Science, 5(1), 14-37. doi:10.1287/orsc.5.1.14 
Pavlou, P. A. (2003). Consumer acceptance of electronic commerce: Integrating trust and risk with the technology acceptance model. International Journal of Electronic Commerce, 7(3), 101-134. doi:10.2307/27751067

Pavlou, P. A., \& Gefen, D. (2004). Building effective online marketplaces with institutionbased trust. Information Systems Research, 15(1), 37-59. doi:10.1287/isre.1040.0015

Pavlou, P. A., Liang, H., \& Xue, Y. (2007). Understanding and mitigating uncertainty in online exchange relationships: A principal-agent perspective. MIS Quarterly, 31(1), 105-136. doi: $10.2307 / 25148783$

Pearlson, K. E., Saunders, C. S., \& Galletta, D. F. (2016). Managing and using information systems, binder ready version: A strategic approach. Toronto, Canada: Wiley.

Petty, R. E., \& Cacioppo, J. T. (1986). The elaboration likelihood model of persuasion. Advances in Experimental Social Psychology, 19, 123-205. doi:10.1016/S00652601(08)60214-2

Rabjohn, N., Cheung, C. M., \& Lee, M. K. (2008, January). Examining the perceived credibility of online opinions: Information adoption in the online environment. Paper presented at Proceedings of the 41st Annual Hawaii International Conference on System Sciences (HICSS 2008), Waikoloa, HI, 2008. IEEE.

Simmel, G. (2004). The philosophy of money. England, UK: Routledge.

Sohn, D. (2014). Coping with information in social media: The effects of network structure and knowledge on perception of information value. Computers in Human Behavior, 32, 145151. doi:10.1016/j.chb.2013.12.006

Stewart, K. J. (2003). Trust transfer on the World Wide Web. Organization Science, 14(1), 517. doi:10.1287/orsc.14.1.5.12810

Stulec, I., Petljak, K., \& Naletina, D. (2018). S-commerce: How to turn \# into \$. InterEULawEast: Journal for the International and European Law, Economics and Market Integrations, 5(1), 1-14. doi:10.22598/ iele.2018.5.1.1

Sussman, S. W., \& Siegal, W. S. (2003). Informational influence in organizations: An integrated approach to knowledge adoption. Information Systems Research, 14(1), 47-65. doi:10.1287/isre.14.1.47.14767

Wang, C., \& Zhang, P. (2012). The evolution of social commerce: The people, management, technology, and information dimensions. Communications of the Associations for Information Systems, 31(5), 105-127. doi:10.17705/1CAIS.03105

Wang, Y., \& Hajli, M. N. (2014). Co-creation in branding through social commerce: The role of social support, relationship quality and privacy concerns. Paper presented at Proceedings of Twentieth Americas Conference on Information Systems, Savannah, Georgia. 
Weber, K., Johnson, A., \& Corrigan, M. (2004). Communicating emotional support and its relationship to feelings of being understood, trust, and self-disclosure. Communication research reports, 21(3), 316-323. doi:10.1080/08824090409359994

Zhong, Y. (2012). Social commerce: A new electronic commerce. Paper presented at Proceedings of Eleventh Wuhan International Conference on e-Business, Wuhan, China. Retrieved May 10, 2018, from http://aisel.aisnet.org/whiceb2011/49 